\title{
Multi-Sensory Technology In Teaching English To Young Learners
}

\author{
Jenny Johana Izquierdo Casadiego \\ Immanuel Kant Baltic Federal University
}

\begin{abstract}
Language is a natural skill in humans and every day more people recognize how important is to be multilingual. Teachers, linguistics, and parents believe that early childhood is the best period to learn the four areas that structure a language which are speaking, listening, reading and writing. When an infant is learning a second language, the educator should design a program with activities that can improve each of these areas and according to Garner, there are multiple intelligences and different styles of learning from the outside world, styles such as auditory, visual, tactile, and kinesthetic.Multisensory Technology states that teaching preschoolers a foreign language recognizes that every child is capable of learning, allowing every individual to acquire knowledge according to his/her characteristics.

The Russian system offers public kindergarten to it's citizens and the main classes are taught in the Russian language with the option of having English classes as an additional service. Classes are two times a week, with a duration of 30 minutes per class and the average group of students has 8 to 10 kids. Based on the experiences and the results observed in different students, the multi-sensory method is the answer for teaching English as a second language in the kindergarten because the method accomodates to different learning styles while developing motivation, attention and energy in the kids.
\end{abstract}

Keywords: Foreign language learning, teaching method, preschoolers, teaching method, Multisensory technology. 